\title{
AS INFLUÊNCIAS DA GLOBALIZAÇÃO NO MOVIMENTO MIGRACIONAL A PARTIR DO PARADIGMA DA COMPLEXIDADE
}

\author{
Odisséia Aparecida Paludo Fontana* \\ Silvia Ozelame Rigo Moschetta ${ }^{\dagger}$
}

\begin{abstract}
Resumo:
O paradigma da complexidade visível na pós-modernidade reporta à globalização e aos movimentos migracionais. O problema que se apresenta é quais as influências da globalização no movimento migracional, a partir do paradigma da complexidade? O objetivo principal é analisar a partir do paradigma da complexidade, quais as influências da globalização no movimento migracional. Os objetivos específicos: compreender a questão paradigmática no âmbito da modernidade, pós-modernidade; investigar globalização e verificar sua influência nos movimentos migratórios. O método científico é o dedutivo. Finaliza-se, apresentando a conclusão sobre a globalização e os movimentos migracionais.
\end{abstract}

Palavras-chave: paradigma da complexidade, pós-modernidade, globalização, migrações, influências.

\section{THE INFLUENCES OF GLOBALIZATION ON THE MIGRATORY MOVEMENT FROM THE COMPLEXITY PARADIGM}

\begin{abstract}
:
The complexity paradigm visible in postmodernity reports the globalization and migratory movements. The problem it presents is what are the influences of globalization in the migratory movement, is it from the complexity paradigm? The main objective is to analyze from the complexity paradigm, which are the influences of globalization in the migratory movement. The specified objectives: to comprehend a paradigmatic issue in the context of modernity, postmodernity; investigate globalization and verify its influence within migratory movements. The scientific method is the deductive. It concludes, presenting a conclusion on globalization and migratory movements.
\end{abstract}

Keywords: complexity paradigm, postmodernity, globalization, migrations, influences.

\footnotetext{
* Possui graduação em Direito pela Universidade do Oeste de Santa Catarina (1996) e pós-graduada pela mesma universidade em Direito Público com ênfase em Direito Constitucional. Mestre pela Universidade Estácio de Sá do Rio de Janeiro. Doutora pela Universidade Federal de Santa Catarina. Atualmente é professora da Disciplina de Direito Previdenciário e professora orientadora de Estágio de Prática Jurídica na área de Direito do Trabalho e Previdenciário na Universidade Comunitária de Chapecó - UNOCHAPECÓ . Coordenadora e Professora do Curso de Pós Graduação em Direito do Trabalho e Processo do Trabalho o e Coordenadora do Curso de Pós Graduação em Direito Previdenciário na Universidade Comunitária da Região de Chapecó - UNOCHAPECÓ e professora da Pós Graduação Stricto Sensu em Direito na Universidade Comunitária da Região de Chapecó. Advogada. Membro do Grupo de Pesquisa: Relações Internacionais, Direito e Poder: cenário e protagonismo dos atores estatais e não estatais e do Grupo de Pesquisa LED - Liberdade, Estado e Desenvolvimento. Membro do Grupo de Estudos Relações Internacionais, Direito e Poder.

${ }^{\dagger}$ Doutora em Direito pela Universidade Federal de Santa Catarina - UFSC. Professora permanente do Programa de Mestrado Acadêmico em Direito UNOCHAPECÓ na Linha de Pesquisa: Direito, Cidadania e Atores Internacionais.
}

Rev. de Direito e Sustentabilidade | e-ISSN: 2525-9687 | Evento Virtual | v. 6 | n. 1 | p. 76-93 | 


\section{INTRODUÇÃO}

As teorias do conhecimento se pautaram no movimento de cientistas e filósofos em busca de afirmações que, em suma, trariam bem-estar para a humanidade, sempre na instigante intenção de aproximação da verdade e da certeza. Uma revolução científica geraria uma transformação do modo de pensar, do mundo do pensamento e do mundo pensado, significando mudar de crença, mudar de ser e mudar de universo. Neste contexto, tem-se os paradigmas simplificador e o da complexidade como fundantes neste recorte científico, por demonstrarem os pilares jurídicos da Modernidade e da Pós-Modernidade.

Com este tom, mas com outro enfoque a globalização se apresenta como um fenômeno que se desenvolve de século a século, com foco no capitalismo, tecnologia, política, ambiente e sociocultural, premissas anunciadas na Modernidade e que permanecem na PósModernidade. A mobilidade é um dos pilares da globalização, a locomoção e a comunicação são os grandes facilitadores para esse movimento transfronteiriço.

Utilizando o fundamento do paradigma da complexidade num espectro multidimensional se apresentam as migrações como significantes de um lado como crise humanitária e por outro como oportunidade de desenvolvimento, por isso a problemática do artigo se circunscreve em a partir do paradigma da complexidade, quais as influências da globalização no movimento migracional? Para desenvolver este problema estabeleceu-se estudar o paradigma da complexidade e sua imbricação com a modernidade e pós modernidade, compreender a globalização e suas influências nos movimentos migratórios. A análise ocorre por meio do método dedutivo e procurar-se-á destacar de que modo a globalização age como fenômeno real nos movimentos migratórios mundiais.

\section{PARADIGMA DA COMPLEXIDADE}

Com embasamento nas teorias do conhecimento, porque conhecer está no rol das significativas descobertas que propiciem a formação e o desenvolvimento da humanidade, estreita-se o assunto para apresentar a utilização do termo "paradigma" no campo gnosiológico. A ruptura epistemológica com a ciência clássica embalou o pensamento de Thomas Samuel Kuhn, que no século XX introduziu nas ciências naturais e físicas e, consequentemente, nas comunidades respectivas a possibilidade de ocorrerem revoluções 
científicas. Mais do que um filósofo, Kuhn foi um historiador da ciência que avaliou as descobertas científicas, sua historicidade, para descrever, ao fim, a revolução. Quando dirigiu seus estudos para a história da ciência, observou que tanto os sociólogos quanto os psicólogos possuíam controvérsias sobre os fundamentos das ciências sociais, situação que não se evidenciava, por exemplo, entre os colegas da astronomia, física, química ou biologia. Diante desse contexto, a intenção kuhniana não foi outra senão descobrir essa diferença e o papel desempenhado na pesquisa científica, o que ele considerou de "paradigma". No início de sua obra A Estrutura das Revoluções Científicas, a consideração sobre paradigma é entoada como as "realizações científicas universalizantes reconhecidas que, durante algum tempo, fornecem problemas e soluções modelares para uma comunidade de praticantes de uma ciência" (KUHN, 2011, p. 13). Em outro momento da obra, já com cunho sociológico, "paradigma é aquilo que os membros de uma comunidade científica partilham e,inversamente, uma comunidade científica consiste em homens que partilham um paradigma" (KUHN, 2011, p. 221, grifo do autor).

Epistemologicamente, não se tem uma definição de "paradigma", mas sim os contornos em que ele surge: ocorre no ambiente científico e social; não é imutável; seu objeto de estudo são questionamentos ou respostas; é coletivo, pois pertence à comunidade científica.

No transcorrer da obra, Kuhn (2011) tece inúmeras considerações distintas acerca de "paradigma", conceito inerente à sua epistemologia, o que suscitou sua manifestação, em 1969, com a escrita do posfácio para dirimir equívocos, dúvidas e responder as críticas. Partindo-se da definição kuhniana, após a escrita do posfácio, paradigma possui dois sentidos: como matriz disciplinar, ou seja, num sentido global, abarcando todos os interesses partilhados por um grupo científico - "matriz" são os elementos de vários gêneros que estão previamente ordenados e "disciplinar" refere-se ao fato de que os pesquisadores estão envoltos em uma disciplina específica; o segundo sentido entoa o exemplar, isto é, isola um gênero particularmente importante de interesse e considera que o resultado que determinada comunidade científica atingiu pode constituir o fundamento da prática ulterior (KUHN, 2011, p. 228-229).

Morin (2007, p. 298-308) apresenta uma redefinição da teoria kuhniana com um glossário que explica vários termos usados nas obras constantes de sua coletânea - entre eles, está "paradigma". Nesse texto, Morin indica a obra A estrutura das revoluções científicas como referência e afirma que o termo "paradigma" foi desenvolvido e redefinido em Méthode 
4 (2011a, p. 204-238), que traz algumas reflexões que contextualizam tal noção, por exemplo: o paradigma contém os conceitos fundamentais ou as categorias-chave da inteligibilidade, bem como o tipo de relações lógicas de atração/repulsão (conjunção, disjunção, implicação) entre os conceitos ou categorias. Os indivíduos conhecem, pensam e agem conforme os paradigmas, culturalmente inscritos neles. Por isso a definição de "paradigma" agrega um caráter semântico para dar sentido; um caráter lógico, pois determina as operações lógicas; e um caráter ideológico com a associação, eliminação e seleção que vigem a organização das ideias. É em razão desse triplo sentido generativo e organizacional que o "paradigma orienta, governa, controla a organização dos raciocínios individuais dos sistemas de ideias que lhe obedecem" (MORIN, 2011a, p. 261).

No mesmo sentido, mas com outro enfoque, Morin (2011b, p. 59) afirma que para se compreender o problema da complexidade é necessário entender que há um paradigma simplificador, vale dizer, um paradigma que põe ordem no universo, por meio de uma lei ou um princípio, pois a simplicidade vê o uno, ou o múltiplo, mas não consegue ver que o uno pode ser múltiplo. Neste contexto, a complexidade encontra-se onde não se pode superar uma contradição.

Em atenção ao recorte deste ensaio, epistemologicamente, a Modernidade se comportou como um momento em que a ciência e a tecnologia garantiriam um controle da natureza e da vida social, evidenciando características de certezas e imutabilidades. No entanto, as incertezas e as mutabilidades apareciam de forma complexa, exigindo uma explicação do mundo, o que levou a uma "revisão profunda dos padrões epistemológicos dominantes" e suscitou um novo paradigma que pudesse compreender essa realidade complexa apresentada e irresolúvel até então (CUNHA, 2006, p. 230).

O paradigma complexo admite um conjunto novo de concepções, visões, descobertas, baseado nos princípios de conjunção e implicação, contrastando com o paradigma simplificador que se apresenta como mutilador, pois sua base está em operações lógicas de disjunção e redução, (MORIN, 2011b, p. 77).

Para o Direito o paradigma simplificador seria o cumprimento estrito à lei, já o paradigma da complexidade necessita de uma estratégia, pois ele "não resolve por si só os problemas, mas se constitui numa ajuda à estratégia que pode resolvê-los" (MORIN, 2011b, p. 83), exigindo do Direito a aproximação das relações sociais, culturas e realidades diferentes 
e divergentes, do sujeito com o objeto, do intérprete com a norma, da casuística ao encaminhamento jurídico factível.

\subsection{MODERNIDADE E PÓS-MODERNIDADE}

Há certa dificuldade em definir Modernidade e Pós-Modernidade, pois são termos polissêmicos que não contemplam uma conceituação unívoca. Parte-se da Modernidade e seus contornos para, após compreendê-la por meio dos seus fundamentos, observar sua “dominação" econômica, política, social, jurídica, filosófica, religiosa, científica e cultural. Mesmo diante de algumas divergências no que se refere à contexto, época e local de seu surgimento, ter-se-á uma explanação que contempla um raciocínio não estigmatizado desse paradigma, a fim de que se possa analisar a significância deste projeto e vistar o arcabouço que se apresenta para a Pós-Modernidade.

Modernidade "refere-se a estilo, costume de vida ou organização social que emergiram na Europa a partir do século XVII e que ulteriormente se tornaram mais ou menos mundiais em sua influência” (GIDDENS, 1990). A Modernidade é constituída como um conjunto de transformações culturais, sociais, econômicas e políticas, sustentadas por ideais filosóficos com vistas à reconfiguração das relações humanas e sociais (BITTAR, 2009, p. 35).

Para Touraine (1994, p. 36), o período moderno iria da Renascença à Revolução Francesa e aos princípios da industrialização em massa da Grã-Bretanha, pois o objetivo era mais pôr em ordem do que em movimento as organizações do comércio, as regras de câmbio, a criação de uma administração pública e do Estado de Direito. Muito embora se sinalize época e local, sabe-se que o paradigma moderno não comporta a análise de um só elemento, uma única data de nascimento, porque ele é um "macroconceito cujas fronteiras são fluidas" (MORIN, 2011b, p. 19).

Com os pilares do projeto filosófico da Modernidade se pode analisar a PósModernidade, a fim de propor, metodologicamente, que se vivencia uma fase de transição paradigmática. O prefixo "pós" anteposto ao termo "moderno"traz uma dose de ambiguidade, que pode variar e se prestar a diversas leituras, podendo descrever diferentes cenários ou panoramas de superação, sucessão ou cesura do moderno (DINIZ, 2006, p. 647, grifo do autor).

Ademais, a ideologia modernista não se reduziu às ideias da filosofia das luzes; ela liderou a ordem econômica por meio do capitalismo, que introduziu no seio das sociedades a 
economia de mercado, configurando "a independência desta em relação aos objetivos próprios do poder político ou religioso e aos efeitos das tradições e dos privilégios" (TOURAINE, 1994, p. 32).

O contexto econômico se apresenta na Modernidade, pelo viés de uma sociedade burguesa e capitalista, embalada pela Revolução Industrial. Indubitavelmente, suas propostas de circulação de bens e mercadorias; livre comercialização entre os povos; permissividade da mais-valia; descoberta de terras na América; negociações com o Oriente - trouxeram um alento para ressignificar práticas medievais. Não se olvide que a ordem religiosa e a científica atravessaram remodelações ou até rupturas, pois se observava a religião aliada ao Estado (pensamento pagão acrescendo a teologia cristã) e a ciência como a grande reveladora dos mistérios da humanidade. Assim, a constituição da Modernidade, além de fatores de ordem econômica, religiosa e científica, baseou-se na dimensão intelectual, com a abertura de universidades, como Bolonha e Paris, caracterizando-se como centros de pensamento lógicoracionais e políticos que referenciavam soberania, governo central e legislação (BITTAR, 2009, p. 37-42).

A permissividade de suscitar um "novo paradigma" reverencia a constatação de que "Há um desassossego no ar.” (SANTOS, 2002, p. 41). Essa afirmação conduz a uma insegurança no presente pelo contorno que se manifesta e uma incerteza no futuro que se aproxima mas ainda é amorfo. Esse abismo (MORIN, 2011b) está marcado por transformações de ordem cultural, econômica, política, social, filosófica, religiosa e jurídica, que compõem uma essência conceitual, léxica e ideária específica de cada dimensão citada, nominada "paradigma", como abordado alhures.

Giddens (1990) também informa que "a força transformadora principal que modela o mundo moderno é o capitalismo"; tanto é assim que a ordem social emergente é capitalista quer em seu sistema econômico, quer em outras instituições.

O ideário moderno, como processo histórico, durou séculos e foi caracterizado por laicização, autonomia, liberdade, industrialização, capitalização, estruturação do Estado, progresso, centralização do poder; por isso termos como "sujeito", “ordem", "soberania" e “Estado" fazem parte do vocabulário moderno (BITTAR, 2009, p. 42-43).

Touraine $(1994$, p. 36) alia a concepção filosófica de Modernidade à econômica, ou seja, razão e sistema capitalista, numa espécie de libertação e revolução num processo inteiramente endógeno, que parte do interior para se expressar. E esse processo endógeno 
gerou uma instabilidade promovida por uma experiência paradoxal entre excessos de determinismo e excessos de indeterminismos, ganhou conotação quando simultaneamente se convivia com a ordem e a desordem, a repetição acelerada e a desestabilização das expectativas, pois as catástrofes pessoais e coletivas eram mais prováveis, os projetos de vida eram sinônimos de riscos inseguráveis, cuja dedução não era outra senão um tempo caótico e catastrófico (SANTOS, 2002, p. 41).

Assim, Santos (2003, p. 34) é enfático quando afirma que se está vivenciando uma fase de transição paradigmática entre o paradigma da Modernidade e um paradigma novo, sem nome, por isso designado paradigma da Pós-Modernidade. Ora, observa-se que a ciência moderna, que tudo pretendia para tornar a vida social e individual progressiva, viu-se convertida a enfrentar um problema sem solução que gerava inúmeras irracionalidades, ou seja, ela própria.

Touraine (1998, p. 19) não utiliza a expressão "pós-modernidade", mas sinaliza o futuro marcado pela ciência, técnica e poderio, que, no entender dele, estão contemplados pela Modernidade. Já Giddens (1990) sugere que esse novo tipo de sistema social, mais que um estado de coisa precedente, está chegando a um encerramento - pós-modernidade, pósmodernismo ou sociedade pós-industrial.

Diante de todo esse contexto, procurou-se explorar ideias e conceitos de inteligibilidade, léxicos que pautam o paradigma da Modernidade e o que se tem como sinalizações para a Pós-Modernidade. Enfim, são inúmeras as razões que admitem uma instabilidade e complexidade, contudo o grande dilema que paira ainda sobre a Pós-Modernidade é o de se ela significaria uma fase intermediária ou avançada dentro da Modernidade ou simbolizaria o início de uma nova etapa no devir sócio-histórico. Disso tudo, extrai-se que a interpretação dada por teóricos, entre eles Jürgen Habermas, é a de que a crise é na Modernidade; no entanto, teóricos sociais pós-modernos, como Boaventura de Souza Santos, entendem que a crise é $d a$ Modernidade.

A afirmação habermasiana "Modernidade - um projeto inacabado" quer dizer que "a modernidade não pode e não quer tomar dos modelos de outra época os seus critérios de orientação, ela tem de extrair de si mesma a sua normatividade". Desta forma, não é outro o entendimento senão o de que o projeto está apenas incompleto, podendo ser colmatado com recursos extraídos dos instrumentos analíticos, políticos e culturais desenvolvidos pela própria Modernidade. Por isso, a Modernidade vê-se referida a si mesma, sem a possibilidade de 
apelar para subterfúgios, o que explica "a suscetibilidade da sua autocompreensão, a dinâmica das tentativas de 'afirmar-se' a si mesma, que prosseguem sem descanso até os nossos dias" (HABERMAS, 2000, p. 1-12, grifo do autor).

Por outro viés, Santos (2003) afirma que o projeto cultural da Modernidade não pode ser findado com termos modernos, eis que não se conseguiria vencer as amarras que a própria Modernidade preparou. Ele defende "algo novo", uma mudança paradigmática expressada por descontinuidades e não meramente subparadigmática, como afirma o entendimento habermasiano (SANTOS, 2003, p. 93).

No mesmo sentido, mas sob outra perspectiva, no âmbito dos estudos históricos, o emprego do termo "pós-modernismo" ressurgiu em 1939 com Arnold Toynbee, que designou de Idade Pós-Moderna o período histórico subsequente à guerra franco-prussiana (18701871), que prepararia o caminho para o posterior advento da Primeira Guerra Mundial (DINIZ, 2006, p. 647; RUSSO, 1996, p. 318).

Por isso, a vertente não era somente cultural, albergava também questões econômicas, que alimentavam a ideia de superação de um "modelo" e a necessidade de "algo novo". Como marca dos problemas econômicos, salienta-se a recessão de 1973, em que o fordismo mergulhou numa crise de superacumulação que fora adiada por muito tempo. Em resposta a isso, surgiu uma "acumulação flexível”, principalmente nos "mercados de trabalho (contratos temporários, mão de obra doméstica e imigrante), processos de fabricação (mudança de fábricas para outros países, produção a toque de caixa), produção de mercadorias (lotes em consignação)", bem como nas operações financeiras desregulamentadas, ou seja, "no mercado de dinheiro e crédito". Desta forma, esse sistema especulativo e inquieto foi a base das várias formas de uma cultura pós-moderna, de cuja realidade e novidade não se podia duvidar - “[...] uma sensibilidade intimamente ligada à desmaterialização do dinheiro, à característica efêmera da moda, ao excesso de simulação nas novas economias". Diante desse contexto, não se poderia afirmar que a acumulação flexível absorveu as formas fordistas; pelo contrário, elas coexistiam mas o que mudou de modo crítico foi "a posição e a autonomia dos mercados financeiros dentro do capitalismo, passando por cima dos governos nacionais, o que significa uma instabilidade sistêmica sem precedentes" (ANDERSON, 1999, p. 94-95).

Para Santos (2003, p. 103), a relação entre Moderno e Pós-Moderno é contraditória, pois não se pode romper tampouco manter uma linear continuidade, já que é uma situação de transição em que há momentos de ruptura e outros de continuidade. A reflexão de que a Pós- 
Modernidade não deixa de visitar a Modernidade, além dos ensinamentos de Morin (2011a, p. 273), ganha a mesma interpretação quando Anderson afirma que o "pós-moderno nunca suplantou completamente o moderno, os dois estando sempre de alguma forma atrasados, como tantos futuros prefigurados e passados recuperados" (ANDERSON, 1999, p. 118, grifo do autor).

Diante do colacionado, percebe-se que dissecar o paradigma da Modernidade requer uma abordagem filosófica, econômica e jurídica para assim conceber, complementar e interpretar a Pós-Modernidade. Mais do que uma época, a Modernidade importou uma consciência que se traduziu para a humanidade como um modo de ser e também de ter. Imbuído desse contexto, opta-se por contemplar uma outra era, uma nova consciência que supera as dicotomias cartesianas e ascende para uma politomia marcada por um sujeito que está no centro, no caso, no umbigo das preocupações jurídicas. Por isso comentar sobre PósModernidade importa, no âmbito do Direito, por exemplo, aceitar certa impotência ante os conflitos que se apresentam, mas também reconhecer uma clarividência na condução de tais superações, buscando o encaminhamento mais adequado e justo.

Em consonância com o relatado, observa-se que a Pós-Modernidade traz em seu âmago a necessidade de um novo formato de condução, e aqui, pelo recorte do escrito um outro olhar para o Direito, que perpassa pelas categorias modernas e se expressa em alternativas jurídicas paraquestões como a globalização e a migração, assuntos que requerem do jurista a compreensão multidimensional desses fenômenos, premissa anunciada pelo paradigma da complexidade.

\section{GLOBALIZAÇÃO}

A Globalização é um fenômeno que abrange as dimensões econômica, política e social. Ao estudar o processo de Globalização na história é possível verificar acontecimentos que contribuíram para o que hoje denomina-sede Globalização. Muito embora o aparecimento efetivo da globalização inicia no século XX, seus primeiros sinais aparecem ainda no final do século XIV, com as descobertas marítimas, como por volta de 1492 com a descoberta da América por Cristóvão Colombo e em 1498 o caminho marítimo para a Índia, por Vasco da Gama (PRELHAZ, 2012, p.3). 
Já nos séculos XVII e XVIII, há outro sinal da globalização, o modelo Westfaliano dos Estados soberanos (o Estado preza pela sua autonomia), é colocado em xeque, pois as fronteiras estatais tornam-se permeáveis, os Estados nacionais sofrem uma série de interferências nacionais, reflexo de um deslocamento ou recolocação de pessoas, capitais, cultura, religião, inserido tudo isto no processo de globalização, além da Revolução Industrial do século XVIII, em que há um avanço tecnológico nas indústrias.

Outro marco histórico para a globalização é o final da Segunda Guerra Mundial em 1945, já no século XX, sendo que se verificou um novo arranjo de sentidos no mundo através da relativização da soberania e da autonomia estatal, com uma sociedade multicêntrica e interdependente, com a influência de novos atores internacionais, como as Organizações não Governamentais(ONGs) e as empresas Transnacionais(ETNS).

O envolvimento crescente dos Estados Unidos na economia mundial, nos anos de 1970, fez renascer o termo globalização em um debate em escala internacional, muito embora desde a década de 1960 muitos estudiosos já tentavam definir o termo globalização, principalmente com o desenvolvimento dos microprocessadores.

Nas suas formas mais visíveis, estas transformações e movimentações estão frequentemente associadas a inovações tecnológicas. Mas tudo leva a crer, que a globalização é algo que desenvolveu-se progressivamente, século a século, inserido no desenvolvimento das sociedades e que também pode ser compreendida por meio de cinco dimensões distintas, mas interligadas: capitalismo, tecnologia, política, ambiente e sociocultural.

$\mathrm{Na}$ dimensão capitalista destacam-se como fatores primordiais o surgimento e ascensão das empresas multinacionais, sendo que o ponto de partida (HELD,et al, 1999) foram as trocas comerciais por meio das viagens marítimas, impactando nos fluxos financeiros mundiais, interligando pontos distantes do mundo.

Giddens(1990) destaca o poder da economia concentrada e controlada majoritariamente por empresas, sendo o estado relegado para uma função reguladora. Assim sendo, o poder das empresas no mercado internacional aumenta através da deslocalização e expansão da cadeia de valores.

Sob a ótica da dimensão capitalista, destaca-se alguns impactos, segundo Davis e Harrigan (2007): as empresas sofreram um impacto a nível global e na formação dos salários, pois segundo os autores, a globalização ao promover a liberalização comercial tem o efeito de maximização da eficiência no mercado, fortalecendo as empresas mais eficientes e reduzindo 
o número de empresas mais ineficientes. Já para os trabalhadores os efeitos são antagônicos, destruindo os chamados empregos bons, expandindo o número dos chamados empregos maus, além da formação de blocos econômicos.

A dimensão tecnológica é a referência na evolução da globalização, pois permite conectar-se com o outro lado do globo terrestre em questão de segundos. Para Langhorne (2001), a revolução das comunicações é de fato a causa da globalização, existindo três fases fulcrais que marcaram esta revolução.A primeira fase começa no Reino Unido, com a Revolução Industrial e a criação do motor a vapor, aliada, no entanto, à invenção e instalação mundial do telégrafo. Adicionalmente estas duas invenções aumentaram exponencialmente a velocidade de transporte de pessoas, produtos e informação. A segunda fase teve início na Segunda Guerra Mundial, mas teve o seu maior desenvolvimento com o final da guerra e o início da Guerra Fria, caracterizando-se pela combinação da criação do motor de propulsão com a invenção de Alexander Bell, o telefone. Com o início da Guerra Fria as duas potências vigentes concentraram-se na corrida ao espaço, desenvolvendo o motor de propulsão, que havia sido criado na Alemanha, o que permitiu lançar satélites no espaço, que ao serem utilizados em conjunto com o telefone criaram, em 1969, uma rede de comunicações intercontinental rápida e de confiança. A terceira fase, deu-se na década de setenta e concentrou-se na utilização do computador como gestor e transmissor de informação, resultando na criação da internet. Nesta última fase destaca-se a criação do microchip, que revolucionou o computador, tornando-o mais rápido, pequeno e eficaz, permitindo assim a transmissão e conservação de maiores quantidades de informação. Numa fase mais recente esta capacidade foi dinamizada ainda mais pela invenção do cabo de fibra ótica, aliada às redes sociais, que cada vez mais tornam-se relevantes neste fenômeno da globalização.

A dimensão política da globalização tem como referência histórica a queda do muro de Berlim, pois permitiu transformar o mundo em um espaço único e difundiu o capitalismo. Mas a dimensão política está totalmente ligada aos governos.

Giddens (1990) apresenta uma divisão em quatro vértices da dimensão política, a economia do mundo capitalista, a divisão internacional do trabalho, os sistemas de estados nacionais e a ordem militar no mundo. Os dois primeiros tem ligação direta com as empresas e a economia e os dois últimos apresentam o caráter político.

São considerados marcos históricos referentes à dimensão política da globalização a assinatura do Acordo de Bretton Woods e a criação de instituições internacionais como a 
Organização das Nações Unidas, a Organização do Tratado do Atlântico Norte e o Banco Mundial (PRELHAZ, 2012, p.12).

Prelhaz (2012, p.12) cita ainda que o Fundo Monetário Internacional, a assinatura do Protocolo de Quioto e a Organização das Nações Unidas para a Educação Ciência e Cultura tiveram um contributo fundamental, aproximando Nações e harmonizando políticas, permitindo assim o desenvolvimento do processo de globalização, assim como o ataque terrorista de 11 de setembro de 2001 que criaram uma nova clivagem entre povos, nomeadamente o denominado ocidente e os países muçulmanos, e a deslocalização de norte para sul e do ocidente para o oriente, com a ascensão dos denominados BRIC, Brasil, Rússia, Índia e China, também são pontos relevantes na disseminação da globalização.

Quanto à dimensão sociocultural da globalização Dreher et al. (2008) apontam a década de sessenta do século XX como fase embrionária da globalização cultural, com revoluções sociais e culturais que resultaram na emancipação da mulher, dos homossexuais e das chamadas minorias étnicas.

A dimensão ambiental tem sofrido efeitos negativos da globalização, tais como o aumento do tráfego aéreo, rodoviário e marítimo, o aumento da atividade industrial e do consumo de combustíveis fósseis, acabam por impactar no ambiente de forma a degradar o mesmo.Held et al. (1999) explica que a difusão da globalização se manifesta através de choques entre ecossistemas previamente separados, poluição e expansão da degradação ambiental transfronteiriça, difusão e deslocalização da poluição à escala global e poluição e degradação dos recursos ambientais comuns.

Muito embora, sabe-se que os estados firmam tratados internacionais no sentido de preservar o meio ambiente, redução na produção de gases, do consumo de combustíveis fósseis, pela preservação das matas e rios, mas ainda há muito que se fazer.

A análise das cinco dimensões demonstram que todas elas de uma forma ou outra se interligam por meio do processo da globalização, quer com efeitos positivos ou negativos, mas demonstram que esse fenômeno está presente e causando impacto na vida de todos os cidadãos, razão pela qual será demonstrado a partir de agora como é conceituado esse processo de globalização.O termo globalização é conceituado de acordo com a definição e compreensão de vários autores, em que levam em consideração a economia, a cultura, as inovações tecnológicas, entre outros fatores. 
O conceito de Globalização implica em um alongamento das atividades sociais, políticas e econômicas através das fronteiras, de tal modo que acontecimentos, decisões e atividades numa região do mundo podem ter significado para indivíduos e atividades em regiões distintas do globo (HELD, 1999).De acordo com o entendimento de Held, a globalização é a possibilidade e além das fronteiras de estender, difundir fenômenos sociais, políticos e econômicos, quebrando as barreiras divisórias entre países, e que isto pode causar vários efeitos de região para região do mundo.

Murteira (2003), apresenta a seguinte definição: a globalização é um processo que tem conduzido ao condicionamento crescente das políticas econômicas nacionais pela esfera mega econômica, ao mesmo tempo que se adensam as relações de interdependência, dominação e dependência entre os atores internacionais e nacionais, incluindo os próprios governos nacionais que procuram por em prática as suas estratégias no mercado global.

Na definição de Murteira (2003), ele apresenta uma reflexão, pois a globalização não é apenas um processo de crescentes políticas econômicas nacionais e internacionais, mas também possibilitam uma interdependência e até mesmo uma dominação exercida por atores internacionais e nacionais, buscando a melhor forma para atingir o mercado global.

O conceito de globalização, dado por Giddens (2000), refere-se a intensificação das relações sociais em escala mundial e as conexões entre as diferentes regiões do globo, através das quais os acontecimentos locais sofrem a influência dos acontecimentos que ocorrem a muitas milhas de distância e vice-versa. As consequências de nossos atos estão encadeadas de tal forma que o que fizemos agora repercute em espaços e tempos distantes. Isto diz respeito às interconexões que se dão entre as dimensões global, local e cotidiana.

É importante ressaltar que para Bauman (1999, pg. 67) a globalização é uma nova e desconfortável percepção das "coisas fugindo ao controle" é que foi articulada (com pouco benefício para a clareza intelectual) num conceito atualmente na moda. O significado mais profundo transmitido pela ideia da globalização é o do caráter indeterminado, indisciplinado e de autopropulsão dos assuntos mundiais; a ausência de um centro, de um painel de controle, de uma comissão diretora, de um gabinete administrativo. A globalização é a "nova desordem mundial".

Enquanto Giddens ressalta a interconexão global que ocorre devido a globalização, Bauman alerta que a globalização é uma desordem mundial, que as coisas fogem do controle, 
há uma indisciplina, não tem um foco, são assuntos mundiais que perpassam o globo terrestre, causando impactos econômicos, políticos, culturais sem ter um eixo central.

Devido a estas interconexões mundiais que levam informações a todo planeta, a essas mudanças de culturas, novos negócios, o estado com as fronteiras abertas, permitem a entrada de pessoas que vem busca de uma nova vida, quer porque o país que vivem está em crise econômica, quer porque os fenômenos ambientais destruíram seus países, quer porque o país de origem vive uma guerra, sendo estas pessoas os imigrantes que devido a globalização cultural, tecnológica ou econômica, atravessam mares, desertos, fronteiras na esperança de uma vida melhor para si e sua família.

\section{AS INFLUÊNCIAS DA GLOBALIZAÇÃO NO MOVIMENTO MIGRACIONAL}

A migração não é um fenômeno recente, acompanha a era moderna e de certa forma se intensificou na pós-modernidade. É possível afirmar que um exemplo de migração em massa ocorreu quando antes da Era Cristã, Moisés conduz os hebreus para a Terra Prometida e a partir daí ela continua na pauta dos assuntos atuais. Mais do que um assunto, ela se apresenta estampada, não como algo natural que se estabelece entre pessoas que buscam melhores condições de trabalho e que inflam a economia do país receptor, mas num contexto de "crise migratória", sobretudo na Europa. (BAUMAN, 2017, p. 7).

Os movimentos migracionais internacionais envolvem um grande número de seres humanos, sendo um fenômeno global que gera efeitos econômicos, políticos, sociais, religiosos, culturais entre outros.

A Organização Internacional para as Migrações define como fluxos migratórios a “contagem do número de migrantes que se deslocam ou têm autorização para se deslocar para (ou de) um país a fim de ter acesso a um emprego ou fixar-se durante um determinado período de tempo"(OIM, 2009, p.29).

Ante esta definição de fluxos migratórios da OIM, percebe-se o quanto este fenômeno é complexo, abrange migrantes movimentando-se, transitando de um país a outro voluntariamente, outros sentem-se obrigados a deixar sua pátria por diversos motivos, como: guerra, problemas ambientais, falta trabalho, ou na busca de novas oportunidades, na grande maioria das vezes está voltado à celeridade de informações que chegam de um lado do globo terrestre ao outro em segundos, motivando-os a deixar seus países de origem e ir conhecer novos horizontes. 
A busca por um padrão de vida decente traz em si constatações: disparidade de renda entre países pobres e ricos; a migração não reduz essa disparidade; a migração conduz para movimentos de diásporas (BAUMAN, 2017, p. 12).

De acordo com o inventário da Organização das Nações Unidas(ONU) de 2019, há cerca de 272 milhões de migrantes no mundo, sendo 51 milhões a mais do que no ano de 2010, e a grande maioria estão na Europa e América do Norte. Dados de 17 de setembro de 2019, atualmente, somam 3,5\% da população global, comparado com 2,8\% em 2000, de acordo com novas estimativas divulgadas pela Organização das Nações Unidas.

Percebe-se que o mundo está cada vez mais interligado, milhões de pessoas estão envolvidas, por meio de laços familiares, trabalho e renda, novas tecnologias, cultura, entre outros. Também não se pode deixar de citar que a migração é um alavanque no desenvolvimento para os próprios migrantes, para seus países de origem e de destino.

Tendo em vista que no ano de 2019 representavam 3,5\% da população global, isto significa que eles produzem mais que o PIB mundial, ultrapassando $9 \%$, ou seja, mais de 3 trilhões de dólares.

Nesse movimento de migrantes a questão da mobilidade ou do deslocamento era um aspecto frágil da globalização, às vezes as pessoas precisavam ficar mais de 30 ou 40 dias em alto mar, viajando, para chegar até o local de destino, porém o desenvolvimento das telecomunicações e das novas tecnologias possibilitaram enormes avanços na mobilidade dos migrantes. Atualmente algumas horas de viagem aérea faz com que se ultrapassem as fronteiras, locomovendo-se de forma mais rápida, sem contar que as telecomunicações e as novas tecnologias facilitaram o contato com familiares que ficaram no país de origem, além de ser possível efetuar transferências bancárias de forma eficaz para ajudar os familiares que vivem na terra natal.

Stiglitz(2004) cita que o fenômeno da globalização permitiu fazer com que os países estreitassem relações, houvesse uma diminuição nos custos de transportes, já que a

\footnotetext{
${ }^{\ddagger} \mathrm{O}$ inventário de migração internacional realizado pela Organização das Nações Unidas é um conjunto de dados divulgados pela Divisão de População do Departamento de Economia e Assuntos Sociais (DESA) da ONU. Disponível em: $<$ (https://nacoesunidas.org/estudo-da-onu-aponta-aumento-da-populacao-de-migrantesinternacionais). Acesso em 17 de março de 2020.
} 
comunicação por meio de tecnologias inovadoras quebrou barreiras, permitindo uma maior circulação de bens, serviços e pode-se dizer que até de pessoas.

Assim, os migrantes quando chegam aos países de destino trazem consigo novas habilidades, novos costumes e aumentam a força de trabalho. Também tornam-se consumidores, aumentando a oferta de empregos nos serviços e comércio, além de refletir na educação,sendo necessário mais professores. Nos países mais desenvolvidos, amenizam os efeitos do progressivo envelhecimento da população.Assim como, representam uma melhor condição de vida nas comunidades dos países de sua origem, enviando parte da renda que auferem, sendo muito relevante para as economias de países menos desenvolvidos.

Entretanto, a migração igualmente se apresenta com impactos negativos, os migrantes muitas vezes são discriminados, tem rendas inferiores aos empregados locais, gerando competitividade entre trabalhadores, laboram em locais de risco e sem proteção, podem sofrer violências físicas e psíquicas, sofrer xenofobia, além de que para seu país de origem podem estar causando uma perda no desenvolvimento, como por exemplo, onde médicos, engenheiros migram para outros países em busca de remuneração melhor.

É de bom alvitre mencionar o contexto da migração, eis que seus pontos de partida são biformes: migrantes econômicos e refugiados, para os países "desenvolvidos" é uma oportunidade de influxo de mão de obra barata e habilidades lucrativamente promissoras, por outro lado os refugiados são "catalogados" como terroristas (BAUMAN, 2017, p. 9).

No entanto, migração e desenvolvimento andam juntos, pois impactam nos lugares que as pessoas viviam, por onde passam e onde se estabelecem. Todos esses lugares afetam a migração: conflitos, mudanças climáticas, oportunidades de trabalho, entre outros elementos que impactam no fenômeno da migração.

Dessa forma, fica evidente que a globalização gera muitas consequências nos fluxos migratórios, quer efeitos positivos ou negativos e impactam na sociedade global.

\section{CONCLUSÃO}

Os movimentos migracionais são fenômenos que atualmente abrangem praticamente todos os países e continentes. Esses movimentos tiveram início há muitos anos, mas de forma lenta, sendo que nas últimas décadas tem se acentuado, sendo a globalização um dos fatores que influenciou de forma drástica a ascendência desses movimentos. 
Tendo em vista que este tema é contemporâneo, a discussão se faz necessária para compreender tais fatos que permeiam a sociedade. Dessa forma, apresentou-se como problema neste artigo: a partir do paradigma da complexidade, quais as influências da globalização no movimento migracional?

Com o intuito de obter uma resposta a este problema, iniciou-se discorrendo sobre "paradigma", apresentando as ideias e Kuhn e Morin, em que se pode dizer que os paradigmas servem para orientar, com um sentido de organização e para compreender a complexidade é necessário entender a o paradigma.Neste contexto, a complexidade encontra-se onde não se pode superar uma contradição, traduz-se numa espécie de teia, in casu, uma teia global.

Na Modernidade, a ciência e a tecnologia garantiriam um controle da natureza e da vida social, evidenciando características de certezas e imutabilidades, enquanto que a PósModernidade traz em seu âmago a necessidade de mudança em várias dimensões: filosófica, artística, econômica, política, religiosa e jurídica; apresenta-se como um novo formato de condução, como a situação dos movimentos migratórios que se instalaram em todo mundo.

A globalização é um dos fatores, aliados às crises econômicas, sociais, guerras, clima, entre outros, que influenciaram os movimentos migracionais internacionais, já que a facilidade em acessar e receber informações por meio das novas tecnologias tem propiciado o deslocamento para outros países, assim como os meios de transporte atualmente são mais rápidos, fazendo com que as pessoas busquem novas oportunidades, culturas e emprego para sobreviver, demonstrando que a globalização contribui de forma efetiva nos movimentos migratórios.

\section{REFERÊNCIAS}

ANDERSON, Perry.As origens da pós-modernidade. Tradução de Marcus Penchel. Rio de Janeiro: Jorge Zahar, 1999.

BARRETO, Vicente de Paulo (Coord.). Dicionário de filosofia do direito. São Leopoldo: Unisinos; Rio de Janeiro: Renovar, 2006.

BAUMAN, Zygmunt. Globalização: As consequências humanas. Tradução Marcus Penchel. Rio de Janeiro: Jorge Zahar Editor, 1999. 2017.

Estranhos à nossa porta. Tradução Carlos Alberto Medeiros. Rio de Janeiro: Zahar,

BITTAR, Eduardo Carlos Bianca. O direito na pós-modernidade e reflexões frankfurtianas. 2. ed. Rio de Janeiro: Forense Universitária, 2009. 
CUNHA, José Ricardo. Direito e complexidade. In: BARRETO, Vicente de Paulo (Coord.). Dicionário de filosofia do direito. São Leopoldo: Unisinos; Rio de Janeiro: Renovar, 2006.

DAVIS, Donald; HARRIGAN, James. Good Jobs, Bad Jobs, andTrade Liberalization.

DiscussionPaper nº. 0607-07, Columbia University, New York, Junho 2007.

DINIZ, Antonio Carlos. Pós-modernismo. In: BARRETO, Vicente de Paulo (Coord.).

Dicionário de filosofia do direito. São Leopoldo: Unisinos; Rio de Janeiro: Renovar, 2006.

GIDDENS, Anthony. The ConsequencesofModernity. Stanford: Stanford University Press,1990. ISBN 9780804718912

.O Mundo na Era da Globalização. Lisboa, Editorial Presença, 2000.

HABERMAS, Jürgen. O discurso filosófico da modernidade: doze lições. Tradução de Luiz Sérgio Repa; Rodnei Nascimento. São Paulo: Martins Fontes, 2000.

HELD, David, Anthony McGREW (et al) .GlobalTransformations: Politics, EconomicsandCulture, Cambridge, Polity Press, 1999.

KUHN, Thomas. A estrutura das revoluções científicas. Tradução de Beatriz Viana Boeira. 10. ed. São Paulo: Perspectiva, 2011.

LANGHORNE, Richard. The ComingofGlobalization: Its

EvolutionandContemporaryConsequences. New York:Palgrave, 2001.

MORIN, Edgar. O método 5: a humanidade da humanidade. Tradução de Juremir Machado da Silva. 4. ed. Porto Alegre: Sulina, 2007.

O método 4: as ideias: habitat, vida, costumes, organização. Tradução de Juremir Machado da Silva. Porto Alegre: Sulina, 2011a.

Introdução ao pensamento complexo. Tradução de Eliane Lisboa. 3. ed. Porto Alegre: Sulina, 2011b.

MURTEIRA, Mário. Globalização, pela invenção dum tempo global e solidário. Lisboa, Quimera, 2003.

ORGANIZAÇÃO DAS NAÇÕES UNIDAS (ONU). Inventário de Migração Internacional. Disponível em: $<$ (https://nacoesunidas.org/estudo-da-onu-aponta-aumento-da-populacao-demigrantes-internacionais)>. Acesso em 17 de março de 2020.

ORGANIZAÇÃO INTERNACIONAL PARA MIGRAÇÃO(OIM). Glossário sobre Migração. Direito Internacional da Migração. Genebra, 2009, n. 22.

PRELHAZ, João Francisco Andrade.Globalização das Migrações.Dissertação em Economia Portuguesa e Integração Internacional.Instituto Universitário de Lisboa - Departamento de Economia, 2012.

RUSSO, Eduardo Ángel. Teoria General del derecho:en la modernidad y en la pos modernidad. Buenos Aires: Abeledo-Perrot, 1996. 